\title{
Gaining Support for Human Factors in an Engineering Design Culture
}

\author{
Judy Village
}

Ryerson University

\section{Shane Dixon}

Ryerson University

W.P. Neumann

Ryerson University

digital.library.ryerson.ca/object/329

Please Cite:

Village, J., Dixon, S., \& Neumann, W. P. (2012). Gaining support for human factors in an engineering design culture. Canadian Association of Researchers on Work and Health (CARWH) Conference, Vancouver, BC.

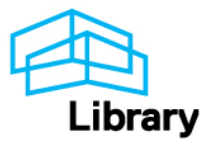




\title{
Gaining Support for Human Factors in an Engineering Design Culture
}

\author{
Judy Village $^{\mathrm{a}, \mathrm{b}}$, Shane Dixon ${ }^{\mathrm{a}}$ and W.P. Neumann ${ }^{\mathrm{a}}$ \\ ${ }^{a}$ Department of Mechanical and Industrial Engineering, Ryerson University \\ ${ }^{\mathrm{b}}$ School of Population and Public Health, University of British Columbia
}

\section{Background and Objectives:}

This paper reports qualitative findings from the first year of a three-year collaborative action research project with a large electronics manufacturer. The goal is to help the organization increase their HF capabilities within their engineering design processes. Our goal, through first-hand observation and participation, is to increase understanding of the facilitators and barriers of HF integration.

\section{Methods:}

Approximately 400 hours were spent on site and 79 interviews and meetings were conducted, either in person or by telephone. Field notes documenting details of events and researcher impressions were recorded in NVivo software. At the end of the first year, one-hour interviews were conducted with four steering committee managers to reflect on the barriers and facilitators of HF integration. Interviews were audio recorded, transcribed, and coded and analyzed for main themes in NVivo. Themes were triangulated with field notes as well as internal communication documents (i.e. meeting minutes, company newsletters, etc.).

\section{Results and Discussion}

Eight themes were classified as facilitators and ten as barriers to HF integration, some of which had overlapping content. Interestingly, six themes appeared as both, depending upon the context, including: notions of compatibility of the HF initiative within the organizations' engineering process (its strategies, other initiatives, internal software, etc).; being "engineering-like" (i.e. project or process with a defined plan, timelines, deliverables and returns on investment); being visible (something demonstrable to show); having support from participants; having the right mix of participants; and permanence of the initiative. HF integration was also facilitated by having good quality initiatives, and having the right champion. Four additional barriers included lack of awareness of the initiative; high complexity; lack of a plan; and company restructuring. Initiatives to integrate HF within the organization generally had a mix of facilitators helping to move it forward (such as being compatible and engineering-like), while at the same time had barriers to overcome (such as low visibility and not having the right mix of people). One participant summarized common sentiments regarding visibility by stating that "everyone can agree that HF is good, but operationalizing HF is a problem because it is not tangible". Some facilitators and barriers to integrating HF into engineering processes in this study have been reported in the ergonomics literature (i.e. the right mix of participants, or permanence) (Haines et al, 2002; VanEerd et al, 2010), or organizational change literature (i.e. support, or the right champion) (Driessen, 2010; Waterson, 2010; Whelen-Berry, 2010). However, factors, which may be specific to the companys' 
engineering design culture, were also found. High visibility of the effort, and being compatible and similar to engineering projects appeared important in this culture. This is consistent with increasing emphasis on Toyota production-like continuous improvement efforts in the organization, such as kaizens, and hoshins. These efforts provide very tangible and visible shop floor changes that can be tracked, documented and reported.

\section{Conclusions}

$\mathrm{HF}$ initiatives may benefit from resembling engineering efforts in an engineering design culture.

\section{Acknowledgements}

This research has been supported by the Workplace Safety and Insurance Board of Ontario.

\section{References}

Driessen MT, Groenewoud, K., Proper, K.I., Anema, J.R., Bongers, P.M., van der Beek, A.J. 2010. What are possible barriers and facilitators to implementation of a Participatory Ergonomics programme? Implementation Science 5(64):1-9.

Haines, H., Wilson, J.R., and Koningsveld, E., 2002. Validating a framework for participatory ergonomics (the PEF). Ergonomics 45, 309-327.

Van Eerd, D., Cole, D., Irvin, E., Mahood, Q., Keown, K., Theberge, N., Village, J., St. Vincent, M. and Cullen, K. 2010. Process and implementation of participatory ergonomics interventions: a systematic review. Ergonomics 53(10): 1153-1166.

Waterson P. and Kolose, S.L. 2010. Exploring the social and organizational aspects of human factors integration: A framework and a case study. Safety Science 48:482-490.

Whelan-Berry K.A. and Sommerville, K.A. 2010. Linking change drivers and the organizational change process: A review and synthesis. Journal of Change Management 10(2):175-193. 